\title{
ANTROPOLOGIA CRIMINAL E PROSTITUIÇÃO: A MATEMATIZAÇÃO DO CORPO SEGUNDO PAULINE TARNOWSKY
}

\author{
Beatriz do Nascimento Prechet* \\ José Roberto Silvestre Saiol ${ }^{* *}$ \\ Laura Nery ${ }^{* * *}$
}

RESUMO: Ao longo do século XIX acompanha-se a conformação de uma série de discursos cientificos, impulsionada por novas demandas da sociedade capitalista urbana e industrial, em plena consolidação. Estes discursos buscavam cada vez mais legitimar sua posição enquanto campo de saber específico, dotados de teorias e métodos próprios. É neste contexto que se observa o surgimento da antropologia criminal, que, por volta da década de 1890 , havia alcançado grande notoriedade por todo o mundo, exercendo influência duradoura. O objetivo deste texto é analisar a matematização do corpo prostituído a partir do estudo antropométrico de Pauline Tarnowsky, um dos grandes nomes da antropologia criminal do final do século XIX e início do século XX. Pretendemos iluminar suas influências teóricas, métodos, argumentos e conclusões acerca do assunto.

Palavras-chave: prostituição; antropologia criminal; degeneração; Pauline Tarnowsky.

\begin{abstract}
We follow along the nineteenth century the shaping of a collection of scientific discourses, driven by new demands of urban and industrial capitalist society under consolidation. Such discourses sought to legitimize their position as specific fields of knowledge, characterized by their own theories and methods. It is in this light that we observe the emergence of criminal anthropology which, around the 1890s, had reached great notoriety and exercised a lasting influence. The purpose of this paper is to analyze the mathematization of the prostituted body from the point of view of the anthropometric study written by Pauline Tarnowsky, a leading authority of criminal anthropology at the turn of the century. We intend to illuminate her theoretical influences, methods, arguments and conclusions on the matter.
\end{abstract}

Keywords: prostitution; criminal anthropology; degeneration; Pauline Tarnowsky

\section{As casas de tolerância}

O filme L'Apollonide: os amores da casa de tolerância (2011), do diretor francês Bertrand

\footnotetext{
* Graduanda do 6o período do curso de licenciatura/bacharelado em História da Universidade do Estado do Rio de Janeiro. Bolsista PIBIC/UERJ. E-mail: biaprechet@gmail.com.

** Graduando do 6o período do curso de licenciatura/bacharelado em História da Universidade do Estado do Rio de Janeiro. Bolsista PIBIC/CNPq. E-mail: joseroberto_hist@hotmail.com.

*** Professora do Departamento de História e do Programa de Pós-Graduação em História da Universidade do Estado do Rio de Janeiro. Email: mnerylaura@gmail.com.
}

Dossiê Transversos: O Corpo na História e a História do Corpo, Rio de Janeiro, v. 05; n. 05; Ano 02. dez. 2015. 
Bonello, conta a história do cotidiano opressivo de um bordel parisiense, durante a chamada Belle Époque. Numa cena curiosa, que enfatiza a rotina de violência e sujeição das mulheres que vivem na casa, a personagem Samira, jovem prostituta, lê atentamente um livro que lhe fora emprestado por um cliente, um médico que, pouco antes, em outra passagem do filme, observara que sua cabeça era muito pequena:

A prostituta entre as mulheres é como um criminoso entre os homens. Observamos um encéfalo vários milímetros menor, devido ao fato de que as prostitutas têm cabeças menores. Portanto, isso significa que apresentam menos massa cerebral. São naturais sua inteligência inferior e sua anormalidade mental. $O$ torpe espírito de algumas pode ser estupor em outras e até mesmo chegar a um estado próximo da idiotice.

O espectador acompanha a angústia crescente de Samira ao ler o trecho, retirado do Estudo antropométrico sobre as prostitutas e ladras, publicado em 1889 pela Dr. a Pauline Tarnowsky, em Paris. Nesse momento, através do efeito de divisão da tela, veem-se quatro ações simultâneas - a da própria leitura, que leva Samira a um choro sentido; a da prostituta Clothilde, que adormece depois de usar ópio; a de uma jovem cujo nome não é mencionado e que atende a um cliente com expressão de total indiferença; e um quarto quadro, no qual vemos uma boneca repetindo gestos mecanicamente, num arremedo grotesco de graciosidade. As imagens fazem um contraponto crítico e algo melancólico à objetividade do estudo. Os três tipos de identificados cientificamente aparecem: aquela que possui o "torpe espírito", a que se entrega ao "estupor", e a chega à "idiotice”. No entanto, há um tipo que não está descrito por Tarnowsky - a prostituta que lê, compreende e lamenta ao ver-se através da letra fria do estudo.

Não se trata aqui de aprofundar a interpretação acerca do filme de Bonello e sua "sociologia poética" do cotidiano do bordel fictício, mas de deixar-se conduzir pela provocação feita pelo filme acerca dessa "ciência precisa": o descompasso entre a objetividade das observações médicas e a experiência vivida pelas personagens. Chama atenção, ainda, a incorporação do estudo ao enredo cinematográfico, sugerindo que a obra era conhecida e considerada uma referência pelos especialistas. Aliás, como nota Sander L. Gilman,

The paper in which Pauline Tarnowsky undertook her documentation of the appearance of the prostitute is repeated word by word in the major late nineteenthcentury study of prostitution and female criminality, La donna delinquente, written by Cesare Lombroso together with his son-in-law, Guglielmo Ferrero, and published in 1893. Lombroso accepts all of Tarnowsky's perceptions of the prostitute ..." (GILMAN, 1985: p. 98) ${ }^{1}$

1 "O artigo em que Pauline Tarnowsky empreendeu seu registro da aparência da prostituta é repetido, palavra por palavra, no grande estudo final do século XIX sobre prostituição e a criminalidade feminina, La donna delinquente, escrito por Cesare Lombroso junto com seu genro, Guglielmo Ferrero, e publicado em 1893. Lombroso aceita todas as percepções Tarnowsky da prostituta ... " (Tradução nossa).

Dossiê Transversos: O Corpo na História e a História do Corpo, Rio de Janeiro, v. 05; n. 05; Ano 02. dez. 2015. 
Os bordéis regulamentados surgem em Paris, em 1804, quando o comissário de polícia Louis Nicolas Dubois organiza oficialmente as casas públicas. O sistema atinge seu auge na década de 1830, sob a chefia de Claude Mangin, quando a prostituição parisiense parecia estar sob controle:

\begin{abstract}
"a casa de tolerância, antitese da espelunca clandestina, é vista como templo de uma sexualidade utilitária. As moças cadastradas, examinadas por médicos de costumes, objeto de um constante treinamento somático, vigiadas com rigor pela dona da casa, devem restituir à família e à sociedade seu parceiro aplacado, mas intato". (CORBIN apud PERROT, 2009: p. 503).
\end{abstract}

Se na ordem burguesa, a prostituição ilegal é sinônimo de sujeira e de doença, já a prostituta regulamentada, oferece diversão segura ao jovem solteiro e um alívio ao homem casado, insatisfeito com o pudor que reina na intimidade do casamento.

Em fins da década de 1890, uma "mutação do desejo" revela os novos gostos e uma nova conduta. Os grandes bordéis parisienses do final do século traduzem a evolução: "agora, cada 'perversão' conta com suas especialistas e refúgios privilegiados" (CORBIN apud PERROT, 2009: p. 522). Nesse ambiente da sedução setorizada, investigações científicas como a conduzida por Tarnowsky, amparada no rigor da amostragem e na minúcia do questionário, oferece um exemplo do deslizamento entre o julgamento moral e a observação médica. Segundo Peter Gay,

na verdade, a medicina e a antropologia do século XIX, que frequentemente alardeavam preconceitos disfarçados de informações fisiológicas, contribuíam para reforçar uma ideologia centrada no sexo masculino: os cérebros femininos são menores e menos desenvolvidos que os dos homens... (GAY, 2002: p. 69).

É nesse contexto marcado pela homologia entre o físico e o moral, que se desenvolve a moderna antropologia criminal: "o controle do indivíduo é essencial para a sobrevivência do grupo" (CORBIN, apud PERROT, 2009: p. 405). ${ }^{2}$ Em Les Maisons de Tolérance. Leur Fermeture, publicado em 1892, o médico e higienista Louis François Fiaux, membro da Sociedade Antropológica de Paris, fez um diagnóstico sombrio, argumentando pelo fechamento das casas públicas. Tomando o partido do abolicionismo, ${ }^{3}$ Fiaux opunha-se à visão utilitarista e

2 A exigência de aprimorar um sistema eficiente de identificação da população é um desafio para as autoridades policiais e judiciárias, especialmente diante da reincidência de criminosos e contraventores. Métodos de identificação antropométrica, como o de Alphonse Bertillon, ou o uso de fotografias nas delegacias tornam mais segura a identificação. Por outro lado, a população ressente-se dos efeitos desses procedimentos sobre a vida privada. Pressionado por inúmeras queixas, Louis Lépine, o comissário de polícia de Paris entre 1899 e 1913, deixa de exigir das proprietárias de bordéis a fotografia das mulheres que frequentam seus estabelecimentos.

$3 \mathrm{O}$ movimento abolicionista opunha-se ao regulamentarismo e considerava a prostituta vítima de seu agente ou explorador.

Dossiê Transversos: O Corpo na História e a História do Corpo, Rio de Janeiro, v. 05; n. 05; Ano 02. dez. 2015. 
atacava a regulamentação da prostituição, assinalando as condições indignas a que essas mulheres eram submetidas.

\begin{abstract}
L'habitude a émoussé toute sensation. Ces femmes ne figurent plus que des mannequins à mécanique invariable réglés pour la mimique sexuelle, se livrant,- le regard, l'esprit, la physionomie ailleurs... Délirantes alcooliques et hystériques, impulsives, persécutées, nymphomanes, toutes les variétés du clavier psychique déséquilibré pullulent dans la maison publique... Les cliniques de la Salpêtrière et des asiles d'aliénés, les infirmeries des prisons en apprennent long sur les névropathies d'origine prostitutionnelle. (FIAUX, 1802: p. 264-269) ${ }^{4}$
\end{abstract}

Louis Fiaux ampara-se na leitura do estudo antropométrico de Tarnowsky, cujos resultados e ideias alinham-se perfeitamente às concepções predominantes na disciplina no alvorecer do século XIX. Segundo Peter Gay, "decididos a realizar o programa do Iluminismo em busca de uma ciência do homem e da sociedade, os vitorianos investigaram com atenção as mazelas sociais: a prostituição, a pobreza, o suicídio" (GAY, 2002: p. 61). Os diferentes saberes buscavam legitimar sua posição enquanto campo específico, dotados de teorias e métodos próprios. É neste contexto que podemos observar o surgimento da Antropologia Criminal, cuja criação convencionou-se atribuir ao italiano Cesare Lombroso (1835-1909) a partir da publicação de $O$ homem criminoso (1871). A propagação da nova ciência se deu tão rapidamente que, por volta da década de 1890, havia alcançado grande notoriedade por todo o mundo, exercendo duradoura influência.

Apesar de tradicionalmente atribuir-se a Lombroso a iniciação da Antropologia Criminal, a literatura nos mostra que, na verdade, a importância de tal autor esteve ligada, sobretudo, à sistematização de uma gama de conhecimentos dispersos. Segundo Émile Laurent, a "ciência jovem” partiu das ideias de homens como Jean-Étienne Esquirol (1772-1840), Bénédict Augustin Morel (1809-1873), Phillipe Pinel (1745-1826), Pièrre Paul Broca (1824-1880), Mathieu Orfila (1787-1853) e Auguste Ambroise Tardieu (1818-1879) (LAURENT, 1891: p. 07). Para Pièrre Darmon, "seria abusivo ver nele, como quer a lenda, o criador da antropologia criminal, ou ciência do homem criminoso, que bem antes dele, já fora objeto da atenção dos alienistas" (DARMON, 1991: p. 37). Segundo o autor, já a partir do século XVI podem-se observar algumas reflexões sobre a relação entre a personalidade e os atributos físicos dos criminosos,

4 "O hábito embotou qualquer sentimento. Essas mulheres não são mais que manequins mecânicos regulados para a mímica sexual, se entregando, - os olhos, a mente, a face em outro lugar... Delirantes alcoólicas e histéricas, impulsivas, perseguidas, ninfomaníacas, todas as variações do teclado psíquico desequilibrado multiplicam-se na casa pública... As clínicas de Salpêtrière e hospícios, as enfermarias das prisões ensinam muito sobre as neuropatias que têm origem na prostituição." (Tradução nossa).

Dossiê Transversos: O Corpo na História e a História do Corpo, Rio de Janeiro, v. 05; n. 05; Ano 02. dez. 2015. 
considerações no entanto escassas, assistemáticas e sem autoridade.

A partir dos estudos de Pinel e de suas categorizações, a Antropologia Criminal começa a se delinear, apoiada também nos estudos de Franz Joseph Gall (1758-1828), onde se afirma a criminologia de componente antropológico, e em James Prichard (1786-1848) e sua teoria do "louco moral", em que os criminosos são "incapazes de discernir o bem do mal e levados ao crime como à coisa mais natural do mundo" (DARMON, 1991: p. 40). Podem-se citar ainda as contribuições de Prosper Lucas (1808-1885), sobre a questão da hereditariedade, e de Morel, em relação aos vícios da modernidade que se refletem, grosso modo, no abastardamento da raça humana. Como todo campo científico em consolidação, a Antropologia Criminal não constituía um corpo coeso. Prova concreta disso é a oposição da escola francesa, representada, sobretudo por Alexandre Lacassagne (1843-1924) e por Émile Laurent, à escola italiana, cujo grande nome era Lombroso. Os primeiros explicariam a criminalidade nata, segundo Laurent, não pelo atavismo ${ }^{5}$, linha defendida por Lombroso, mas sim pela pausa no desenvolvimento e pela degeneração, além de trazerem à baila a dimensão social do assunto. Ainda de acordo com Darmon, a principal diferença entre os precursores aqui citados e o italiano está na ênfase concedida por este aos atributos físicos dos criminosos em detrimento daqueles que estariam atrelados ao estudo de anomalias psíquicas dos delinquentes. (DARMON, 1991: p. 42) Destacamos finalmente as contribuições de Alphonse Bertillon (1853-1914) na descoberta do método de identificação antropométrica (LAURENT, 1891: p. 10) - essencial para a problematização desenvolvida por Pauline Tarnowsky.

Nome destacado pelo Journal of the American Institute of Criminal Law and Criminology, em 1911, Tarnowsky já era, por volta de 1890, uma referência no campo, participando ativamente de congressos de Antropologia Criminal, nos quais se destacavam suas contribuições à questão da prostituição. A médica teve formação como sifilologista. Não há certeza sobre sua data de nascimento e morte: segundo Keely Stauter-Halsted e Nancy M. Wingfield, ${ }^{6}$ ela teria vivido entre 1848 e $1910 .^{7}$ Pouco se sabe sobre onde teria feitos seus estudos, mas é correto afirmar que ela foi discípula de Cesare Lombroso, com quem mantinha

5 Reaparecimento de uma característica genética após algumas gerações.

6 Introduction: The Construction of Sexual Deviance in Late Imperial Eastern Europe. Disponível em: <<http://muse.jhu.edu/journals/journal_of_the_history_of_sexuality/summary/v020/20.2.stauter-halsted01.html >>. Acesso em 28/ set. 2014.

7 Nota veiculada no Journal of the American Institute of Criminal Law and Criminology lamenta seu recente falecimento. Vol. 2, No. 2 (Jul., 1911), pp. 270-271. Disponível em: 〈<http://www.jstor.org/stable/1132962〉〉. Acesso em 28/set. 2014.

Dossiê Transversos: O Corpo na História e a História do Corpo, Rio de Janeiro, v. 05; n. 05; Ano 02. dez. 2015. 
boas relações.

\section{Matematizando o corpo prostituído}

A partir de um trabalho realizado por Bénédict Augustin Morel, De la formation du type dans les variétés dégénérées, que buscava entender a fisionomia das formas exteriores e interiores dos corpos degenerados, ${ }^{8}$ a fim de analisar, reconhecer e provar que as suas particularidades degenerativas são causadas por transmissões hereditárias, Tarnowsky interessou-se em investigar dois tipos de corpos considerados degenerados: as prostitutas e as ladras. Baseado no estudo antropométrico - ou seja, no estudo das medidas corporais -, a pesquisa considera as condições concretas que levavam as entrevistadas à prostituição. No entanto, o questionário acaba revelando também as questões e inquietações que as envolviam. Nesta breve reflexão, examinaremos apenas a parte dedicada às prostitutas e seus corpos matematizados.

Para a sociedade oitocentista, burguesa e, em geral, moralista, a prostituição era vista como um mal (ou, na melhor das perspectivas, um mal necessário), comparável a guerras e crimes e era considerada quase tão grave quanto estes. $\mathrm{O}$ ponto de partida moralista acerca da prostituição, evidentemente, fundamenta o estudo de Tarnowsky. A repulsa à profissão transparece em toda a pesquisa da médica, que desejava entender e analisar as motivações que levaram essas mulheres a entrar nessa vida "marginal", considerada desonesta e maldita. Elas buscavam uma alternativa à miséria em que viviam ou realmente possuíam algum tipo de desvio moral e genético? A análise partiu, principalmente, das mulheres que se tornaram prostitutas, por algum motivo abandonaram a profissão e, depois, retornaram. A hipótese da lucratividade da profissão justificaria a reincidência. "Aussi ne sont-ce pas celles qui succombent à des causes fortuites qui font l'objet du notre étude, mais bien celles qui exercent leur métier de plein gré, s'y complaisent, et ne désirent pas en changer." (TARNOWSKY, 1889: p. 3).

O estudo de Tarnowsky foi feito em 1889, no Hospital de Kalinkine, em São Petersburgo, instituição que dispunha de uma ala especialmente destinada a atender as prostitutas atingidas pela sífilis e por outras doenças venéreas. A metodologia utilizada pela médica, a princípio, resumiu-se à observância de três condições. A primeira delas foi a escolha de 150 prostitutas, devidamente registradas nas casas de tolerância com, pelo menos, três anos de

8 Entende-se por corpo degenerado aquele cujas características particulares de espécie foram modificadas, passando a possuir uma condição inferior.

9 "Também não são que aquelas que sucumbem a causas fortuitas que são objeto do nosso estudo, mas as que exercem a sua profissão de forma voluntária, cedem a ela e não querem mudança.” (Tradução nossa)

Dossiê Transversos: O Corpo na História e a História do Corpo, Rio de Janeiro, v. 05; n. 05; Ano 02. dez. 2015. 
profissão. Para Tarnowsky, esse período representava a fase de adaptação a essa vida e caracterizava estas mulheres como prostitutas profissionais. O segmento analisado deveria ser composto por mulheres de idades próximas, da mesma raça e oriundas da mesma província.

A segunda condição era a de que as mulheres fornecessem todo tipo de informação sobre o seu passado - família, status social, doenças e hábitos, sem a qual a análise minuciosa não poderia ser realizada. Justamente por trabalhar com a memória pessoal das entrevistadas, houve muita dificuldade no recolhimento dos dados, que, segundo a autora, eram muitas vezes imprecisos ou pouco relevantes. A última condição diretiva era de natureza racial: as prostitutas deveriam ser nativas das províncias do que a autora define como Grande Rússia, excluindo-se também as estrangeiras, as tártaras e semitas e aquelas com pai ou mãe estrangeiros. Por isso, a amostragem só contemplou as russas de nascença: todas aquelas que fossem dos confins da Rússia ou da chamada pequena Rússia foram descartadas.

Segundo a médica, para o êxito de um trabalho exploratório e analítico era necessário dispor de um universo grande de objetos diversos para que os mesmos pudessem ser comparados entre si, a fim de obter respostas mais precisas. Por esse motivo, Tarnowsky analisou também 100 mulheres da área rural, que viviam somente da agricultura, e 50 mulheres cultas, cursando escola superior. Todas elas "normais" e "honestas". Atendendo às condições mencionadas acima e estabelecidas as comparações, o estudo dividiu, por fim, as prostitutas em três categorias: "profissionais", "eventuais" e "habituais".

Para realizar as medições no corpo dessas mulheres, Tarnowsky utilizou os métodos e os instrumentos de Pièrre Broca e de Paul Topinard (1830-1911) e estabeleceu vinte e sete pontos importantes a serem minuciosamente medidos e descritos. Porém, devido ao fato de sua pesquisa ser baseada em prostitutas hospitalizadas por doenças venéreas, houve a impossibilidade de medir suas partes íntimas, visto que muitas tinham os órgãos genitais protegidos por curativos. As mulheres honestas, por sua vez, recusavam despir suas partes íntimas, alegando sentir nojo e vergonha do seu baixo corporal.

Portanto, devido às dificuldades encontradas para a análise desses corpos, o estudo antropométrico de Pauline ficou restrito à cabeça e foi dividido em seis partes principais diamétre antéro-postérieur, diamétre transversal maximum, courbe horizontale totale, distance bizygomatique, distance bigoniaque e índice céphalie - e estabeleceu que a marca de 165 milímetros deveria ser tomada como parâmetro para as comparações entre o universo misto de mulheres pesquisadas. Ao concluir as medições, Tarnowsky percebeu que as prostitutas possuíam

Dossiê Transversos: O Corpo na História e a História do Corpo, Rio de Janeiro, v. 05; n. 05; Ano 02. dez. 2015. 
a caixa craniana menor, em comparação às camponesas e às mulheres cultas, e, por isso, sua capacidade intelectual era muito baixa. Além disso, nos resultados obtidos em todas as seis categorias base, as prostitutas obtiveram resultados sempre inferiores aos das duas outras classes de mulheres.

Uma vez que os resultados indicavam claramente que a degeneração nas prostitutas seria real e irrefutável, devido à diferença tão grande entre os números comparados, o passo seguinte seria buscar as causas que levavam à dégénérescence physique. Com esse fim, Pauline Tarnowsky pesquisou o passado dessas mulheres à procura de qualquer vestígio que pudesse explicar a disparidade em relação às mulheres normais e honestas. E descobriu, nos pais, as causas dessa anormalidade.

A degeneração, para ela, era fruto das transmissões genéticas e não tinha nenhuma ligação com as doenças sexualmente transmissíveis como havia pensando previamente, principalmente com a sífilis, pois cinquenta e oito prostitutas nunca contraíram a doença e mesmo assim apresentavam anomalias. Observe-se que Pauline compartilhava da opinião de diversos médicos, como Magnus Huss, Benedict Morel, Legrand du Saulle, Lentz e Legrain, segundo os quais a degeneração era causada não por uma má formação genética, mas pela transmissão dos defeitos de seus pais. Defeitos esses entendidos como vícios, com destaque para o alcoolismo, eleito um dos principais motivos da degeneração dessas mulheres.

Ao longo do trabalho, é possível notar que Tarnowsky contrapõe a escolha da profissão aos princípios socialmente aceitos da boa conduta, deixando claro que os vícios transmitidos para as filhas, durante a gestação, afetam-nas não somente no âmbito físico, mas principalmente no moral. Segundo ela, embora o "bom senso moral" de todo ser humano não admita a preferência por essa ocupação, sua existência é fato inegável (TARNOWSKY, 1889: p. 06). Segundo a médica, a prostituição era, portanto, duplamente fruto da imoralidade e do desvio das faculdades mentais do ser humano, causadas por esses vícios. Tal constatação é interessante, pois demonstra claramente como a dimensão moral dos sujeitos, e não apenas a física, à época, estaria também sob a esfera de atuação do saber médico.

Entretanto, Tarnowsky deixa claro que não descartava de todo o determinismo econômico. Embora atribuísse a este um papel secundário, a médica levava em conta a miséria em que essas mulheres muitas vezes se encontravam, considerando-a entre os fatores que as levavam a entrar no métier. Esta nuance pode sinalizar uma tendência apontada por Pièrre Darmon nos trabalhos de Cesare Lombroso: a de introduzir aos poucos a importância dos fatores

Dossiê Transversos: O Corpo na História e a História do Corpo, Rio de Janeiro, v. 05; n. 05; Ano 02. dez. 2015. 
sociológicos em suas análises, sem, contudo, abandonar a noção do "criminoso nato". (DARMON, 1991: p. 64-65)

Diante de um quadro amplo de medições e de inferências relevantes, Pauline realiza um segundo momento exploratório para aprofundar ainda mais seu estudo de caso. Instigada pela necessidade de examinar as particularidades percebidas em cada uma dessas mulheres, ela divide as prostitutas em duas categorias. $\mathrm{O}$ primeiro grupo compreende aquelas que são privadas de inteligência e estão sempre num estado de "idiotice". Ela denomina esse grupo como Affaiblissement de l'Intelligence, e entende que essa deficiência é uma debilidade do próprio “espírito".

Dentro desse grupo encontramos as prostitutas "obtusas"10 e as "despreocupadas"11. As "obtusas" são desprovidas de qualquer tipo de sentimento e de sensibilidade e não possuem nenhum tipo de interesse. Segundo a médica, "beber, comer e dormir, são seus únicos prazeres" (TARNOWSKY, 1889: p. 68). Já as “despreocupadas", por mais que também apresentem um "enfraquecimento da inteligência”, são dadas ao riso fácil, à alegria, e mostram-se interessadas pelas coisas da vida, porém são totalmente imprevisíveis. De acordo com Tarnowsky, elas se distinguem por uma mudança de humor impressionante, passando rapidamente do riso ao choro e vice-versa, não sendo exigentes e contentando-se com pouco. (TARNOWSKY, 1889: p. 73)

Finalmente, o segundo grupo compreende um grande número das mulheres pesquisadas, pois é nele que se inserem aquelas que sofrem de problemas nervosos. Aí encontramos aquelas de "caráter histérico" e as "impudicas". As de "caráter histérico" teriam um exagerado instinto sexual e todas as particularidades inerentes ao um tal caráter. Para Tarnowsky, essa "superexcitação exagerada" constituiria uma anomalia (TARNOWSKY, 1889: p. 81). As "impudicas", por sua vez, seriam loucas, desprovidas de consciência do bem e do mal, do certo e do errado: em uma palavra, seriam "insanas". Aponta a médica que a inexistência de pudor e de honestidade caracteriza todo esse grupo: "cette cécité innée du sentiment de la pudeur, de la honte qui les caracterize toutes, les mène souvent aux confins d'un cinisme inconscient qui ne laisse pas de choquer par as naïvité étrange", ${ }^{12}$ observa ela (TARNOWSKY, 1889: p. 85).

10 Nesse sentido, a autora define as "obtusas" como sendo mulheres "ignorantes", "tapadas", "desprovidas de um mínimo senso crítico".

11 Ambos os adjetivos, "obtusas" e "despreocupadas", foram traduzidos livremente do francês: "les obtuses" e "les insouciantes".

12 "Essa cegueira inata em relação ao sentimento de pudor, de vergonha, que caracteriza a todas, as leva frequentemente aos confins de um cinismo inconsciente que não deixa de chocar pela sua estranha ingenuidade." (Tradução nossa)

Dossiê Transversos: O Corpo na História e a História do Corpo, Rio de Janeiro, v. 05; n. 05; Ano 02. dez. 2015. 
Até aqui foi possível observar, portanto, algumas diretrizes téorico-metodológicas que orientam a forma como Tarnowsky reúne e analisa os dados coletados e como apresenta suas conclusões. Mas é importante destacar também como estes dados se apresentam em sua obra para além dos quadros antropométricos. Um exemplo pode ser esclarecedor: trata-se do caso de Alexandrine A., 23 anos, observação n. 38:

Les parentes d'A ... son natifs de Saint-Pétersbourg. Père portier alcoolique dypsomane. Mort em 1870 à lâge de 45 ans, emporté par une phtisie pulmonaire. Mère laborieuse et sobre. Santé délicate. Souvent des migraines; actuellement est agée de 52 ans. À eu 15 enfants dont 13 morts em bas âge. Testent deux filles, toutes deux prostituées [...]. $\mathrm{Al}$... a une tête légèrement oxycéphale. Figure agréable quique trait irréguliers. Dents blanches et saines, mais écartées les unes des autres. [...]. Fut rachetée par un homme qui l'entretien pendant un an et demit et qui la rendit mére. Mais elle se lassa d'une vie tranquille et rangée; querelles, jalousie, séparation et retour à la maison de tolèrance qu'elle habite actuellement depuis quatre ans, et où ele sembre se plaire. Ne sait pas, et ne se preocupe nullement de ce qu'est devenu son enfant qu'elle abandona au père. [...]. A... est três personelle, égoïste, aime ses aises et les plaisirs. Elle est très soignée de sa personne, mais témoigne une absence complete de sens moral. [...] Elle en a été libérée - mais y est revenue de plein gré, et trouve son existence fort supportable, ne désirant pas la changer por un travail quelconque.", cf Pauline Tarnowsky, "Étude anthopométrique sur les prostituées et les voleuses.(TARNOWSKY, 1889: p. 89-91) (13 $^{13}$

O estudo de caso de Alexandrine é um dos vários contidos no volume. Como salientado anteriormente, aos dados antropométricos - omitidos do exemplo acima - são acrescidos os dados biográficos das prostitutas entrevistadas. Neste caso, Al... é uma representante do grupo das "impudicas" - e caracterizadas, como dissemos, por sua "falta de percepções éticas" (TARNOWSKY, 1889: p. 85) - ora, Al.. “demonstra uma falta completa de senso moral”. Verificou-se também a característica da reincidência na prostituição, a anomalia física no crânio e a ênfase concedida ao histórico familiar e, neste caso, particularmente, à dipsomania alcoólica do pai de Al... Finalmente, destacou-se também uma referência à questão da maternidade, uma vez que, à época, era muito comum, dentro do repertório da Antropologia Criminal, a crença na esterilidade das prostitutas ou, como no caso de Al..., a falta de extinto materno.

13 "Os pais de Alexandrine A... são nativos de São Petersburgo. Pai portador de dipsomania alcóolica. Morreu em 1870 aos 45 anos, devido a uma tuberculose pulmonar. Mãe laboriosa e sóbria. Saúde delicada. Geralmente com enxaquecas; atualmente com 52 anos. Teve 15 filhos, mas 13 morreram com baixa idade. Restaram 2 filhas, todas as duas prostitutas. [...] Al... tem uma cabeça ligeiramente oxicefálica. Figura agradável, embora traços irregulares. Dentes brancos e sãos, mas afastados uns dos outros. [...] Após a morte do pai, Alexandrine foi acolhida por um orfanato, do qual acabou expulsa, passando sucessivamente por vários empregos até tornar-se doméstica numa casa de tolerância: $\quad$... foi [re]comprada por um homem, que a sustentou durante um ano e meio e a tornou mãe [...]. Mas ela se cansou de uma vida tranquila e reta; querelas, ciúmes, separação e retorno à casa de tolerância que ela habita atualmente há 4 anos, e onde ela parece se satisfazer. Não sabe e não se preocupa com o que aconteceu com seu filho, que ela abandonou com o pai. [...] A. é muito egocêntrica, egoísta, ama suas vontades e os prazeres. Ela cuida muito bem de sua pessoa, mas demonstra uma falta completa de senso moral. [...] Ela, mesmo liberada, retornou por vontade própria e tornou sua existência bastante suportável, não considerando mudá-la por um trabalho qualquer." (Tradução nossa)

Dossiê Transversos: O Corpo na História e a História do Corpo, Rio de Janeiro, v. 05; n. 05; Ano 02. dez. 2015. 


\section{Considerações finais}

Ao fim deste breve percurso através da Antropologia Criminal conduzido pelo estudo antropométrico de Pauline Tarnowsky, surgem mais inquietações do que respostas concretas. A pesquisa empreendia por Tarnowsky constituiu um esforço expressivo voltado para a identificação de sujeitos desviantes através da experimentação empírica. Neste sentido, pode-se sugerir uma clara inspiração no ideal naturalista de identificação, classificação e construção num repertório taxinômico aos moldes de Carolus Linnaeus (1707-1778), voltado, contudo, para o campo da criminologia, no qual estaria inserida também a prostituição.

\footnotetext{
Muitos postulados em circulação no campo da Antropologia da segunda metade do séc. XIX eram tributários de práticas e concepç̃es estimuladas já no campo da História Natural de fins do XVIII, tais como a própria possibilidade de interpretar o homem enquanto objeto de estudo. (BRAGA e STEPHEN, s/d: p. 06)
}

$\mathrm{Na}$ chave da matematização dos corpos aqui proposta, tal forma de saber é bastante ilustrativa da maneira como se acreditava poder alcançar, através de medidas precisas e instrumentos antropométricos, da frenologia, da fisiognomia e dos estudos anatômicos, a "essência criminosa" dos sujeitos, seu grau de degeneração e de curabilidade e, em alguns casos, sugerir formas de correção - inserindo-se para isso em disputas com outros campos como o jurídico, por exemplo.

Sob esta perspectiva, os esforços destes médicos estariam voltados para uma espécie de medicalização do crime, como se verifica no estudo aqui focalizado. Se, para Tarnowsky, como se salientou acima, "o bom senso moral" rejeita a opção pelo meretrício, a prostituição só poderia então ser entendida e explicada como uma condição hereditariamente transmissível. Hipótese cientificamente verificada e comprovada, sobretudo, através das medições cranianas que revelariam os sinais da degeneração, a qual, consequentemente, levaria aquelas mulheres à prostituição. Neste caso, a preferência por tal ofício constituiria um epifenômeno da condição degenerada daquelas mulheres.

Os resultados alcançados pela autora se inserem dentro de um campo cientifico e teórico mais extenso que buscava a identificação dos estigmas da degeneração. Assim, ao observar as considerações de Tarnovsky sobre a esterilidade das prostitutas (LAURENT, 1891: p. 103), aceitas também por Lombroso e Guillaume Ferrero (DARMON, 1991: p. 63), ou a relação estabelecida entre a capacidade craniana e a inteligência - laço encontrado desde os primórdios da craniometria em meados do século XVIII-, percebe-se como tais proposições ligavam-se ao 
conjunto mais amplo de convicções e pressupostos que mobilizavam o pensamento médico da época, refletindo simultaneamente aspirações científicas e interesses sociais. Tais formas de conhecimento se produziam e se disseminavam entre esses pensadores e tinham também grande impacto entre os leigos.

\section{Referências Bibliográficas:}

\section{Fontes primárias:}

Journal of the American Institute of Criminal Law and Criminology. Vol. 2, No. 2 (Jul., 1911), pp. 270-271. Disponível em: <http://www.jstor.org/stable/1132962>. Acesso em 28/set. 2014. LAURENT, Dr. Émile. L'anthropologie criminelle et les nouvelles théories du crime. Paris: Société d'Éditions Scientifiques, 1891. Source gallica.bnf.fr / Bibliothèque municipale de Lyonpart Dieu. Disponível em: http://gallica.bnf.fr/ark:/12148/bpt6k5824756h.r=pauline+tarnowsky.langFR. Acesso em jun. 2014.

TARNOWSKY, Pauline. Étude anthropométrique sur les prostituées et les voleuses. Paris: E. Lecrosnier et Bébé, 1889. Source gallica.bnf.fr / Bibliothèque municipale de Lyon-part Dieu. Disponível em: 〈http://gallica.bnf.fr/ark:/12148/bpt6k5788932f.r=pauline+tarnowsky.langFR>. Acesso em jun. 2014.

\section{Fontes secundárias:}

BRAGA, Daniel Dutra Coelho; STEPHAN, Diana Ferreira. A craniometria lombrosiana: entre a história natural e a criminologia. Pôster dialogado. Disponível em: $\langle$ http://www.hcte.ufrj.br/downloads/sh/sh4/posteres/DanielDutraDianaStephan.pdf $>$. Acesso em jun. 2014.

DARMON, Pierre. Médicos e assassinos na Belle Époque: a medicalização do crime. Rio de Janeiro: Paz e Terra, 1991.

FIAUX, Louis.Les maisons des tolérance, leur fermeture. Paris: Georges Carré Éditeur, 1892. Disponível em: < http://gallica.bnf.fr/ark:/12148/bpt6k61809r> Acesso em set. 2014. FOUCAUlT, Michel. De Outros Espaços. In MOTTA, Manoel Barros (Organizador). Ditos e Escritos. Rio de Janeiro: Forense Universitária, 2006. Vol. III p. 411-432. 
GILMAN, Sander L. Difference and Pathoplogy: Stereotypes for sexuality, Race, and Madness. Ithaca-London: Cornell Univesity Press, 1985.

SÁ, Guilherme José da Silva e; SANTOS, Ricardo Ventura; RODRIGUES-CARVALHO, Claudia; SILVA, Elizabeth Christina da. Crânios, corpos e medidas: a constituição do acervo de instrumentos antropométricos do Museu Nacional na passagem do século XIX para o XX. História, Ciências, Saúde - Manguinhos, Rio de Janeiro, v.15, n.1, p.197-208, jan.-mar. 2008.

SANTOS, Elaine Maria Geraldo dos. Antropologia criminal nos primeiros anos da República. In: SIMPÓSIO NACIONAL DE HISTÓRIA, 22. 2003, João Pessoa. Anais do XXII Simpósio Nacional de História: História, acontecimento e narrativa. João Pessoa: ANPUH, 2003. Disponível em: <http://anpuh.org/anais/wp-content/uploads/mp/pdf/ANPUH.S22.720.pdf >. Acesso em jun. 2014.

STAUTER-HALSTED, Keely; WINGFIELD, Nancy M. Introduction: The Construction of Sexual Deviance in Late Imperial Eastern Europe. Disponível em: $<$ http://muse.jhu.edu/journals/journal_of_the_history_of_sexuality/summary/v020/20.2.stauter -halsted01.html>. Acesso em 28/ set. 2014.

\section{Como citar:}

PRECHET, Beatriz do Nascimento; SAIOL, José Roberto Silvestre; NERY, Laura. Antropologia Criminal e prostituição: a matematização do corpo segundo Pauline Tarnowsky. Revista Transversos. "Dossiê: O Corpo na História e a História do Corpo". Rio de Janeiro, Vol. 05, nº 05, pp. 61-73, Ano 02. dez. 2015. Disponível em: <http://www.e-publicacoes.uerj.br/index. php/transversos>. ISSN 2179-7528. DOI: 10.12957/transversos.2015.19796.

Dossiê Transversos: O Corpo na História e a História do Corpo, Rio de Janeiro, v. 05; n. 05; Ano 02. dez. 2015. 